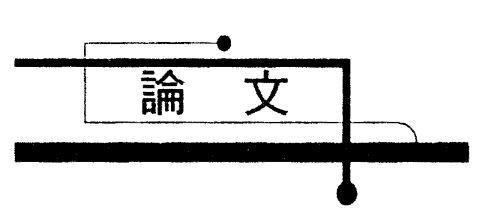

\title{
Mass Transfer between Particles and Liquid in Gas-Liquid-Solid Three-Phase Upflow through a Vertical Tube
}

\author{
KIKUCHI Ken-ichi $^{* *}$ MIZUKAMI Yutaka ${ }^{* * *}$ ENDA Shigeyuki ${ }^{* * *}$
}

TAKAHASHI Hiroshi $^{* *}$ SUGAWARA Takuo ${ }^{* *}$

\begin{abstract}
A b stra ct Solid-liquid mass transfer coefficients have been obtained by measuring the ion-exchange rate in a gas-liquid-solid three-phase upflow through a vertical tube. The three phase is composed of nitrogen gas, an electrolyte solution, and cation-exchange resin beads of $941 \mu \mathrm{m}$ in diameter. Other experimental variables are slurry velocity, gas velocity, and temperature. The mass transfer coefficients increased according to increases in the slurry velocity, gas velocity, and temperature. The experimental results have been correlated by the following equation, previously proposed for a solid-liquid two-phase tube flow :
\end{abstract}

$$
\begin{aligned}
& S h=2+0.47\left(\varepsilon^{1 / 3} D_{p}^{4 / 3} / v\right)^{0.63} S c \\
& 60<\left(\varepsilon^{1 / 3} D_{p}^{1 / 3} / v\right)<400,269<S c<641, m_{d}<0.01
\end{aligned}
$$

where $\varepsilon, D_{p}, v$, and $m_{d}$ are energy dissipation rate per unit mass of liquid, particle diameter, kinematic viscosity, and delivered concentration of particles, respectively.

Keywords: Mass transfer, Three-phase flow, Vertical tube, Three-phase reactor, Ion exchange, Energy dissipation rate

\section{INTRODUCTION}

Gas-liquid-solid three-phase flow reactors have been employed in various engineering fields such as liquefaction of coal and catalytic hydrogenation of oil, recently as a fermentor in the continuous culture with immobilized cells. The reactors have a remarkable feature that the flow rate of solid is widely variable as well as those of gas and liquid. However, little information on the reactors restricts a wide application to industrial

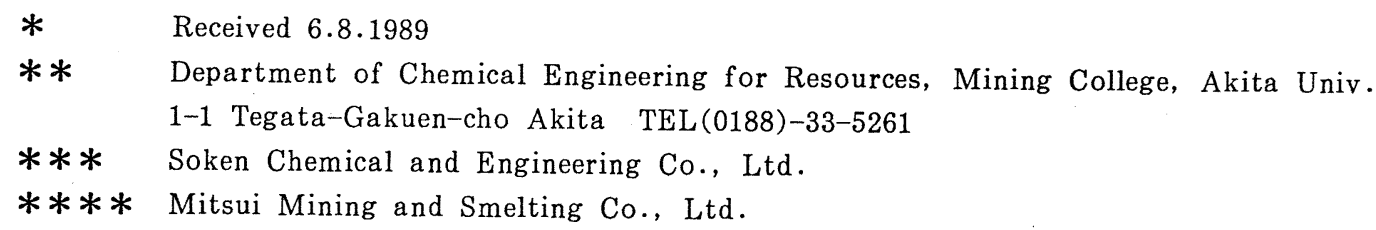


processes. Some work on the three-phase tube reactors has been reported concerning hydrodynamics (recently, Toda et al. 1982 ; Hatate et al. 1986a, 1986b) and heat transfer (Hatate et al., 1987). But few researches are found as for mass transfer. Meanwhile, we have studied the mass transfer in liquid-solid two-phase tube flow (Ohashi et al., 1979, 1981, 1982 ; Kikuchi, 1984). The mass transfer coefficients between a liquid and particles have been obtained in vertical upflow and horizontal flow at low particle concentration (less than 1\%). A single correlation equation for the coefficients has been proposed with the specific power group including energy dissipation rate. The equation has been extended to the two-phase flow at high particle concentration (less than 40\%) with the concept of effective energy dissipation rate (Kikuchi et al., 1987).

The purpose of this work is to obtain fundamental information on the mass transfer in three-phase tube flow. The liquid-solid mass transfer coefficients are measured in the three-phase upflow composed of nitrogen gas, electrolyte solution, and cation-exchange resin beads. The coefficients are correlated with the specific power group including energy dissipation rate on the basis of knowledge from the studies on the hydrodynamics and mass transfer in liquid-solid two-phase tube flow.

\section{EXPERIMENTAL APPARATUS AND PROCEDURE}

The experimental apparatus and procedure are based on those for liquid-solid two-phase tube flow (Ohashi et al., 1979). A schematic diagram of the experimental apparatus is shown in Fig. 1. The reactor (1) was made of the Plexiglas tube of $3.0 \mathrm{~cm}$ in inner diameter and $7.07 \mathrm{~m}$ in reacting-section length. The gas distributor (6) was provided at $0.22 \mathrm{~m}$ down stream from the elbow (5). Two types of distributor were used : one has 16 holes of $0.3 \mathrm{~mm}$ in diameter for low gas velocities; the other has 8 holes of $1.5 \mathrm{~mm}$

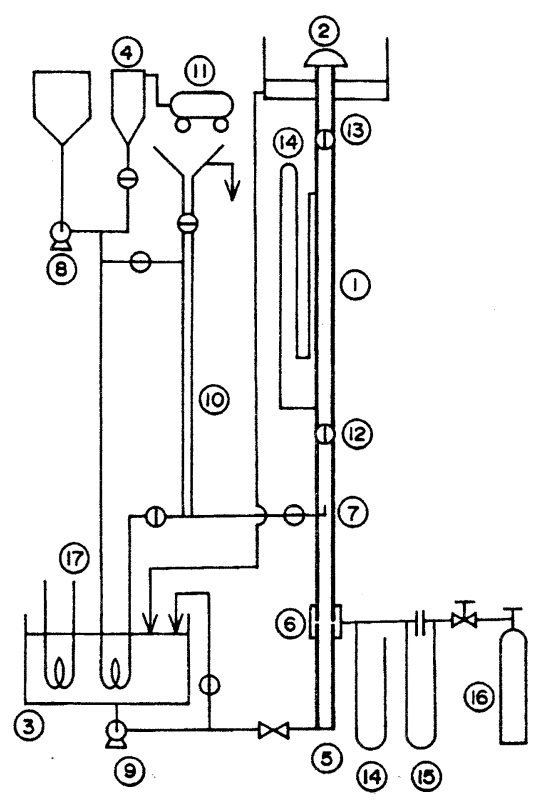

Fig. 1 Schematic diagram of of experimental apparatus.

(1) Reactor tube ; (2)particle separator ;

(3) stock tank; (4)head tank; (5)elbow;

(6)gas inlet; (7)particle inlet; (8), (9)chemical pumps ; (10) particle holder; (11) compressor ; (12), (13) ball valves; (14) manometer; (15) orifice meter ; (16) nitrogen bomb; (17) heat exchanger. 
in diameter for high gas velocities. The injection nozzle of particle (7) was positioned at $1.74 \mathrm{~m}$ downstream from the elbow (5), and its size was 10 (8) $\mathrm{mm}$ in outer (inner) diameter and $60 \mathrm{~mm}$ in length in vertical section. The particle separator (2) was attached for instantaneous separation of particles from liquid at reactor outlet.

The particles used were styrene-type sulfonic acid cation-exchange resin beads (DIAION SK1B) of $941 \mu \mathrm{m}$ in diameter and $1280 \mathrm{~kg} / \mathrm{m}^{3}$ in density.

In the mass-transfer experiment, the particles (sodium form resin beads) and nitrogen gas were supplied into the tube, forming the three-phase flow with potassium chloride solution, the concentration of which was $1 \times 10^{-3} \mathrm{kmol} / \mathrm{m}^{3}$. During the transport through a reactor tube, sodium ion in the particles was exchanged with potassium ion in the solution. The solution and particles were separately collected at the reactor exit without recycling. Slurry velocity and particle concentration were determined from the weights of the solution and particles sampled during the period of constant injection rate of particles. The cation concentrations in the solution were analysed with the atomic absorption method.

The gas holdup in the tube was estimated by measuring the volume of the space provided by closing the valves (12) and (13) instantaneously.

\section{CALCULATION OF MASS TRANSFER COEFFICIENT}

The overall ion-exchange rate should be determined by the mass transfer rate of potassium ion from liquid phase to resin phase under the present experimental conditions where the concentration of potassium ion is very dilute and the fractional attainment of ion exchange is less than $4 \%$ (Ohashi et al., 1979). Thus the material balance for potassium ion through the reactor tube gives Eq.(1) at steady state:

$$
\begin{aligned}
& -\frac{\mathrm{d}}{\mathrm{d} x} \int_{S} e_{\mathrm{L}} u_{\mathrm{L}} c \mathrm{~d} s-\int_{S} k_{\mathrm{L}} a\left(c-c_{i}\right) \mathrm{d} s=0 \\
& c=c_{0} \quad \text { at } \quad x=0
\end{aligned}
$$

Equation (1) is solved with Eq. (2) on the following assumptions: the profile of cation concentration across the cross-section is flat; the cation concentration at liquid-solid interface is negligibly low; the distributions of gas, liquid, and solid holdups are uniform along flow axis. As a result, Eq. (3) is obtained for the liquid-solid mass transfer coefficient $\bar{k}_{\mathrm{L}}$ :

$$
\bar{k}_{\mathrm{L}}=\bar{u}_{S}\left(\frac{D_{p}}{6 L}\right)\left(\frac{V_{\mathrm{L}}}{V_{S}}\right) \ln \left(\frac{c_{0}}{c_{e}}\right)
$$

where

$$
\bar{k}_{\mathrm{L}}=\int_{S} e_{S} k_{\mathrm{L}} \mathrm{d} s / \int_{S} e_{S} \mathrm{~d} s
$$




$$
\bar{u}_{S}=\int_{S} e_{S} u_{S} \mathrm{~d} s / \int_{S} e_{S} \mathrm{~d} s
$$

The particle velocity $\overline{u_{S}}$ is expressed by Eq. (6) with the gas holdup $\overline{e_{G}}$ and the particle velocity based on slurry $\vec{u}_{\mathrm{s}}^{*}$.

$$
\bar{u}_{S}=\bar{u}_{S}^{*} /\left(\bar{e}_{\mathrm{L}}+\bar{e}_{S}\right)=\bar{u}_{S}^{*} /\left(1-\bar{e}_{G}\right)
$$

Consequently,

$$
\bar{k}_{\mathrm{L}}=\left(\frac{\bar{u}_{S}^{*}}{1-\bar{e}_{G}}\right)\left(\frac{D_{p}}{6 L}\right)\left(\frac{V_{\mathrm{L}}}{V_{S}}\right) \ln \left(\frac{c_{0}}{c_{e}}\right)
$$

The liquid-solid mass transfer coefficients were calculated by substituting the observed values into $\mathrm{Eq} .(7)$, where $\vec{u}_{\mathrm{s}}^{*}$ was estimated by our previous equation for liquid-solid two-phase tube flow (Ohashi et al., 1980) according to the recommendation of Toda et al. (1982).

\section{EXPERIMENTAL RESULTS AND DISCUSSION}

The experimental conditions are listed in Table 2. The flow patterns observed under these conditions were mainly bubble flow, partly slug flow and churn flow, being almost explained with the flow-pattern map of Taitel et al.(1980) as shown in Fig. 2 .

Table 1 Experimental conditions

\begin{tabular}{lr}
\hline Temperature $\left[{ }^{\circ} \mathrm{C}\right]$ & $20,30,40$ \\
Slurry velocity $u_{S \mathrm{~L} 0}[\mathrm{~m} / \mathrm{s}]$ & $0.07-3.0$ \\
Gas Velocity $u_{G 0}[\mathrm{~m} / \mathrm{s}]$ & $0-2.0$ \\
Particle concentration $m_{d}\left[\mathrm{~m}^{3} / \mathrm{m}^{3}\right]$ & less than 0.01 \\
$R e_{\mathrm{L}}\left(=\overline{u_{\mathrm{L}}} D_{T} / v\right)$ & $1.86 \times 10^{4}-1.12 \times 10^{5}$ \\
$S c(=v / D)$ & $269-641$ \\
$c_{0}\left[\mathrm{kmol} / \mathrm{m}^{3}\right]$ & $1 \times 10^{-3}$ \\
\hline
\end{tabular}

\section{1 Gas Holdup}

The gas holdup for gas-liquid two-phase system has been firstly measured on various conditions, as shown in Fig. 3 . The gas holdup increases with increasing gas velocity

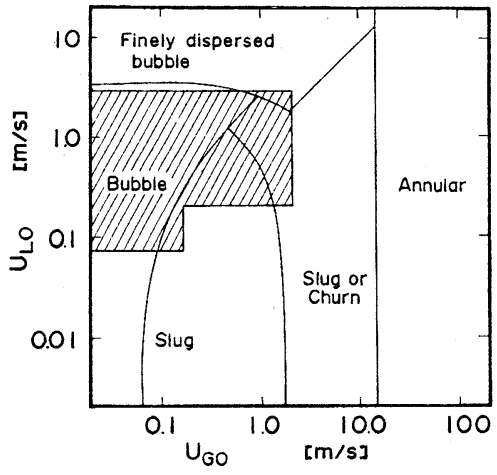

Fig. 2 Flow-pattern map of gas-liquid two-phase flow given by Taitel et al. Hatched area denotes the region of experimental conditions in this work. 


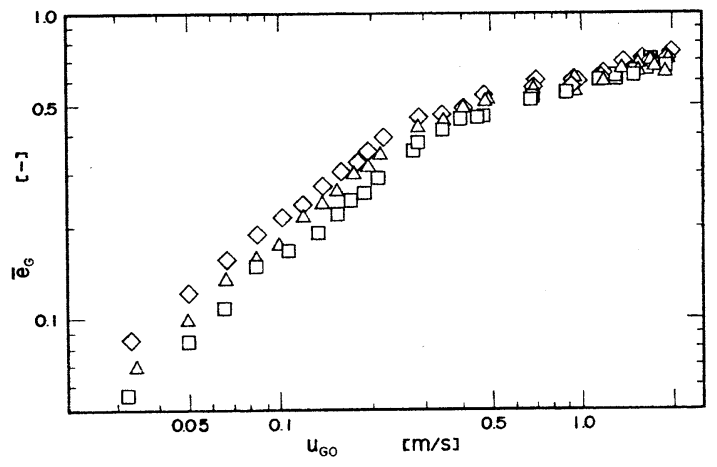

Fig. 3 Effects of gas velocity and liquid velocity on gas holdup in gasliquid two-phase upflow through vertical tube. Liquid velocities : $\diamond 0.25 \mathrm{~m} / \mathrm{s} ; \triangle 0.35 \mathrm{~m} / \mathrm{s}$; $\square 0.50 \mathrm{~m} / \mathrm{s}$.

and decreasing liquid velocity. A number of correlations have been published for estimating the gas holdup of gas-liquid two-phase flow through a vertical tube. Typical correlations have been evaluated by the use of the present data of the gas holdup in gas-liquid two-phase system. Figs. 4 (a) and 4 (b) show the comparisons of the values calculated by the Akagawa's equation (Akagawa, 1957), and the Hughmark's equation (Hughmark, 1962), respectively, with the observed values. The values by the Akagawa's equation almost agree with the observed ones, while those by the Hughmark's equation are about $30 \%$ smaller than the observed ones.

The gas holdup for gas-liquid-solid three-phase system, essential to the calculation of mass transfer coefficient by Eq. (7), would be the same as that for gas-liquid two-phase system under the present experimental conditions, where solid concentration is less than $1 \%$.
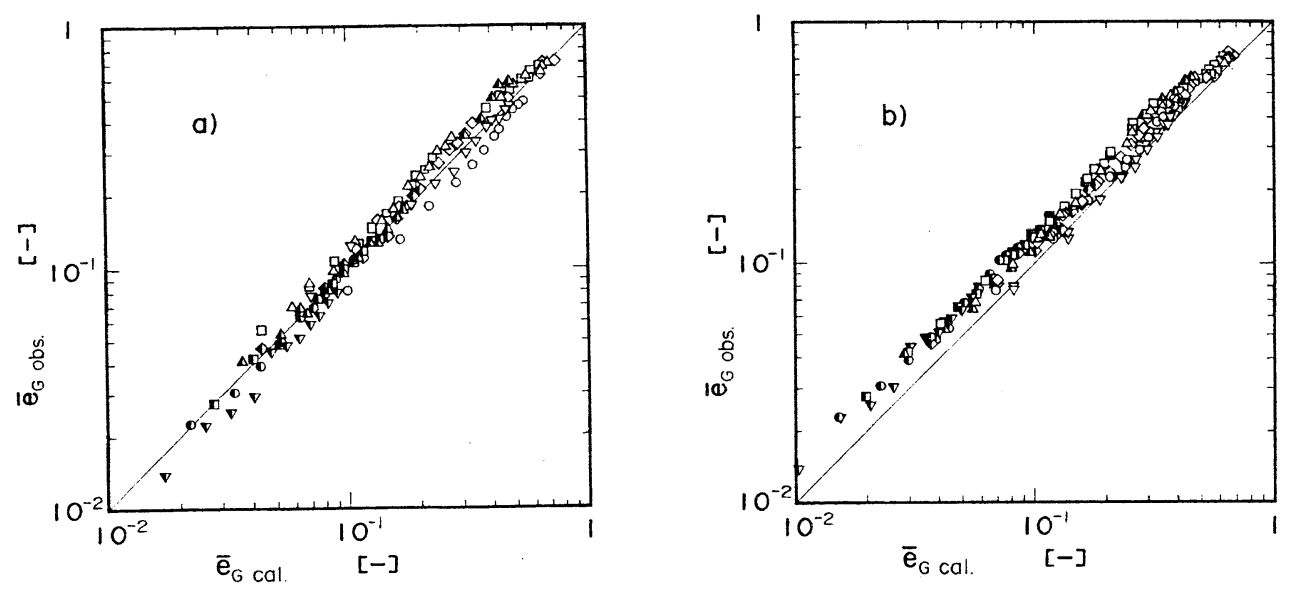

Fig. 4 Comparisons of observed values of gas holdup in gas-liquid two-phase upflow through vertical tube with values calculated by Akagawa's equation (a) and by Hughmark's equation (b). Liquid velocities : $\bigcirc 0.07 \mathrm{~m} / \mathrm{s} ; \nabla 0.10 \mathrm{~m} / \mathrm{s}$;

$\diamond 0.25 \mathrm{~m} / \mathrm{s} ; \triangle 0.35 \mathrm{~m} / \mathrm{s} ; \square 0.50 \mathrm{~m} / \mathrm{s} ; \triangle 0.75 \mathrm{~m} / \mathrm{s} ; \triangle 1.0 \mathrm{~m} / \mathrm{s} ; \square 1.5 \mathrm{~m} / \mathrm{s} ;$

( $2.0 \mathrm{~m} / \mathrm{s} ; \nabla 3.0 \mathrm{~m} / \mathrm{s}$. 


\section{2 Mass Transfer Coefficient}

Figs. 5, 6, and 7 show some examples of the experimental results, where the lines were calculated by the correlation equation discussed later. The mass transfer coefficient increases with increasing temperature, which was also observed in the solid-liquid two-phase tube flow (Ohashi et al., 1979). Fig. 6 shows plots of mass transfer coefficients against slurry velocity as a parameter of gas velocity. The observed values of mass transfer coefficient at the gas velocity of zero agree well with a line calculated by the previous equation for liquid-solid two-phase tube flow (Kikuchi, 1984):

$$
S h=2+0.47\left(\varepsilon^{1 / 3} D_{P}^{4 / 3} / v\right)^{0.63} S_{c}^{1 / 3}
$$

In Fig. 6 the mass transfer coefficients at the gas velocities of 0.5 and $2.0 \mathrm{~m} / \mathrm{s}$ are observed to be larger than at the gas velocity of zero, being affected by slurry velocity more at high slurry velocities than at low slurry velocities. Figure 7 represents that the dependence

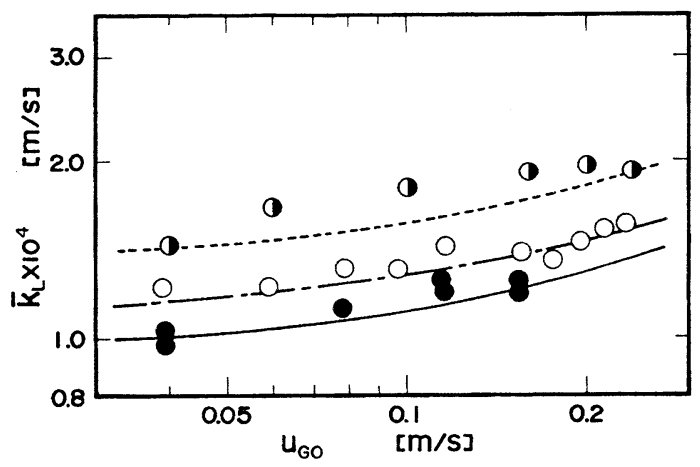

Fig. 5 Effects of gas velocity and temperature on solid-liquid mass transfer coefficient.

Slurry velocity $: 0.75 \mathrm{~m} / \mathrm{s}$.

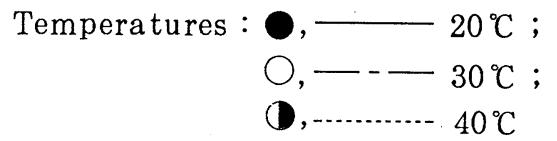

(Lines were calculated by Eqs. (8) and (9)).

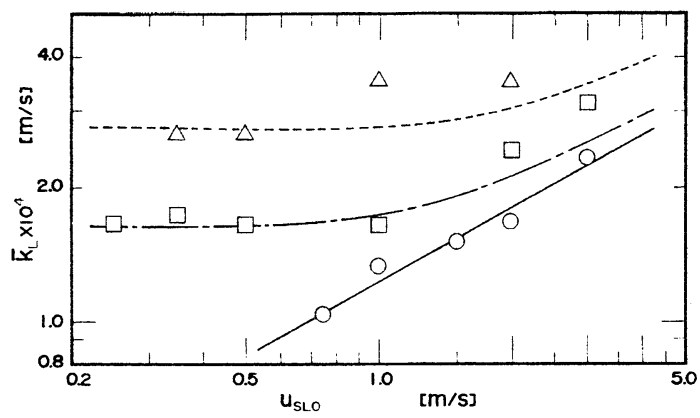

Fig. 6 Effects of gas velocity and slurry velocity on liquidsolid mass transfer coefficient. Temperature : $30^{\circ} \mathrm{C}$.

Gas velocities : $\bigcirc,-0 \mathrm{~m} / \mathrm{s}$,

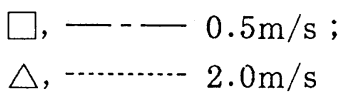

(Lines were calculated by Eqs. (8) and (9)).

Fig. 7 Effects of gas velocity and slurry velocity on liquid-solid mass transfer coefficient.

Temperature : $30^{\circ} \mathrm{C}$.

Slurry velocities : $\triangle,-0.35 \mathrm{~m} / \mathrm{s} ; \mathbf{x}^{\mathrm{s}}$
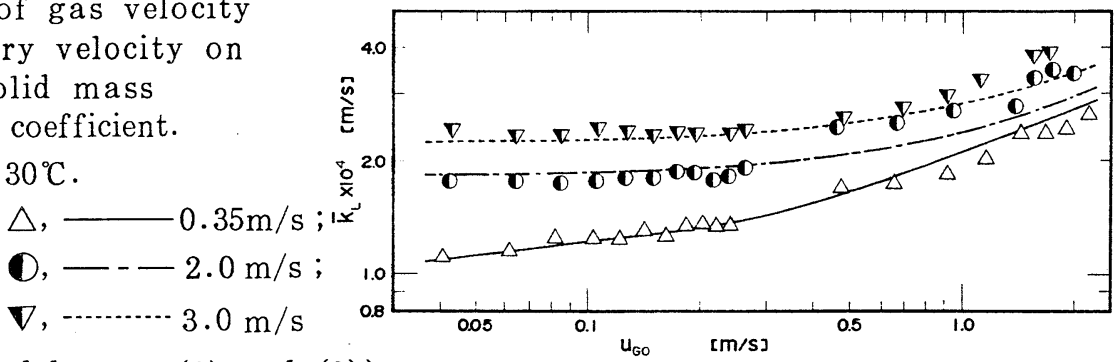

(Lines were calculated by Eqs. (8) and (9)). 
of mass transfer coefficient on gas velocity is larger at high gas velocities than at low gas velocities. The observed values of the mass transfer coefficient at high gas velocities seem to increase proportionally to about 0.25 th power of gas velocity. The tendency of this experimental results is similar to that for suspended bubble columns, where the mass transfer coefficients are in proportion to the 0.25 th power of gas velocity (Sano, Yamaguchi and Adachi, 1974). Fig. 7 suggests that the mass transfer at high gas velocity is mainly promoted by the turbulent eddies produced through the energy of gas flow. The same suggestion is also made by Fig. 6 : the mass transfer at high slurry velocity is enhanced by the turbulent eddies from the energy of slurry flow. Therefore the energy of gas flow and slurry flow could play an important role in the mass transfer in gas-liquid-solid three-phase flow.

\section{3 Correlation of Mass Transfer Coefficient}

We demonstrated previously that the liquid-solid mass transfer coefficient in liquid-solid two-phase tube flow was successfully correlated by Eq. (8) with the specific power group including energy dissipation rate $\varepsilon$ (Ohashi et al., 1979, 1981, 1982 ; Kikuchi, 1984), and revealed that Eq. (8) almost agreed with the correlation equations published for such mass transfer systems as stirred tanks, suspended bubble columns, and even single particles, fixed beds, and fluidized beds (Kikuchi, 1984).

Now, we will apply the correlation method to the present mass transfer system of gas-liquid-solid three-phase tube flow as follows: the energy balance through a reactor tube gives the energy dissipation rate for three-phase tube flow by Eq. (9).

$$
\varepsilon=\frac{g}{\rho_{\mathrm{L}} \bar{e}_{\mathrm{L}}}\left\{u_{T} \rho_{T}-\left(u_{G 0} \rho_{G}+u_{\mathrm{L} 0} \rho_{\mathrm{L}}+u_{S 0} \rho_{S}\right)\right\}+\left(\frac{u_{T}}{\rho_{\mathrm{L}} \bar{e}_{\mathrm{L}}}\right)\left(\frac{\Delta p}{L}\right)_{f}
$$

where $\rho_{T}=\rho_{G} \bar{e}_{G}+\rho_{\mathrm{L}} \bar{e}_{\mathrm{L}}+\rho_{S} \bar{e}_{S}, \quad u_{T}=u_{G 0}+u_{\mathrm{L} 0}+u_{S 0}$.
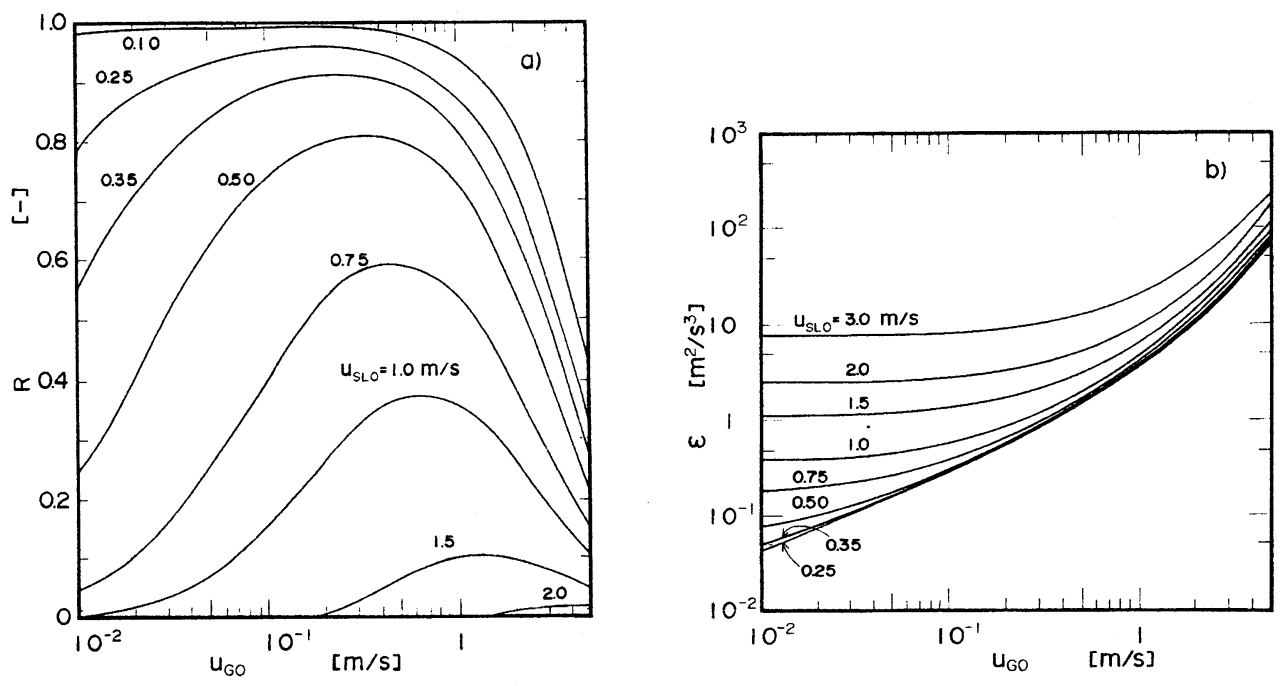

Fig. 8 Effects of gas velocity and slurry velocity on $R$ and (a) $: R,(\mathrm{~b}): \varepsilon \quad(R$ is defined by the ratio of the first term to $\varepsilon$ in Eq. (9)) . 
The first and second terms of Eq. (9) mean the contributions of potential energy and frictional energy, respectively. Fig. 8 (a) shows the ratio of the first term to $\varepsilon$ in Eq. (9), $R$ against gas velocity as a parameter of slurry velocity. The values of $\varepsilon$ are also shown in Fig. 8 (b). In the figures the solid velocity $u_{s 0}$ and the solid holdup $\overline{e_{S}}$ were taken to be zero since they were negligibly small under the present experimental conditions. The friction loss, $(\Delta p / L)_{f}$, was estimated by the equation of Toda et al. (1982) and the gas holdup $\overline{e_{G}}$ by Akagawa's equation (1957). The values of $R$, i.e., the contribution of potential energy to $\varepsilon$, decrease with increasing slurry velocity, having a maximum with increasing gas velocity. The dependence of $\varepsilon$ on gas velocity and slurry

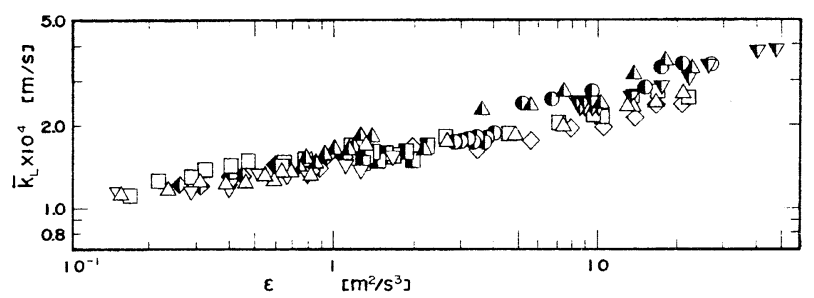

Fig. 9 Correlation of mass transfer coefficient with energy dissipation rate defined by Eq. (9). Temperature : $30^{\circ} \mathrm{C}$. Slurry velocities : $\nabla 0.1 \mathrm{~m} / \mathrm{s} ; \diamond 0.25 \mathrm{~m} / \mathrm{s} ; \triangle 0.35 \mathrm{~m} / \mathrm{s}$;

$\square 0.50 \mathrm{~m} / \mathrm{s} ; \triangle 0.75 \mathrm{~m} / \mathrm{s} ; \triangle 1.0 \mathrm{~m} / \mathrm{s} ; \square 1.5 \mathrm{~m} / \mathrm{s} ; \bigcirc 2.0 \mathrm{~m} / \mathrm{s} ; \nabla 3.0 \mathrm{~m} / \mathrm{s}$.

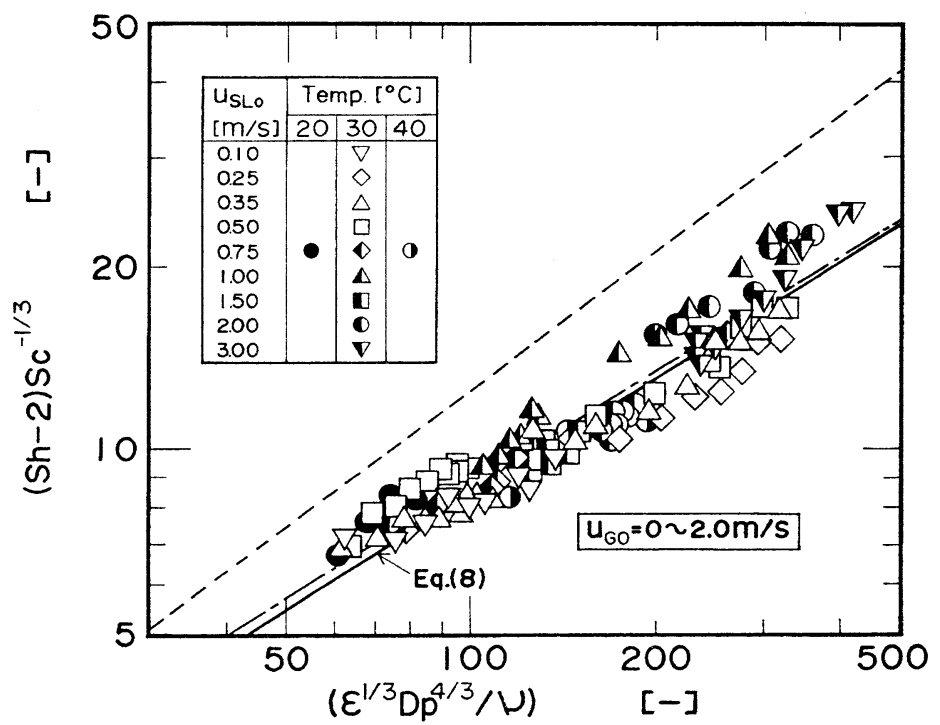

Fig. 10 Correlation of Sherwood number to specific power group and Schmidt number for gas-liquid-solid three-phase tube flow. Lines :-- - equation of Levins and Glastonbury (1972) for stirred tank ; .......... equation of Sano et al . (1974) for suspended bubble columns. 
velocity is similar to that of the mass transfer coefficient $\bar{k}_{\mathrm{L}}$ shown in Fig.7.

Fig. 9 shows a correlation of all the data at $30{ }^{\circ} \mathrm{C}$ including those in Figs. 6 and 7 with the energy dissipation rate defined by Eq. (9). The figure indicates that the energy dissipation rate is a suitable parameter for the correlation in gas-liquid-solid three-phase tube flow. Fig. 10 shows a correlation of Sherwood number to Schmidt number and specific power group by the use of all the observed values for three-phase tube flow. In the correlation, the diffusivity was estimated from the equation of Kataoka et al. (1968) with due consideration of the effect of electric fields. The experimental results are satisfactorily correlated to be a single equation over a wide range of conditions, coinciding with Eq. (8) for solid-liquid two-phase tube flow expressed by a solid line in the figure. In addition those also agree well with the equation of Levins and Glastonbury (1972) for stirred tanks, though lying about $40 \%$ below the equation of Sano, Yamaguchi and Adachi (1974) for suspended bubble columns.

The lines in Figs. 5, 6, and 7 were calculated by Eq. (8) with Eq. (9), agreeing with the observed values better for bubble flow regime than for slug flow regime or churn flow regime which were shown in Fig. 2. Consequently, Eq.(8), previously proposed for solid-liquid two-phase tube flow, is applicable to explain the experimental results for gas-liquid-solid three-phase tube flow in the range where $60<\left(\varepsilon^{1 / 3} D_{P}^{4 / 3} / v\right)<400,269<\mathrm{S}_{C}<$ 641 , and $m_{d}<0.01$.

\section{CONCLUDING REMARKS}

The experiment was conducted to obtain fundamental information on the mass transfer in the gas-liquid-solid three-phase tube flow composed of nitrogen gas, electrolyte solution, and ion-exchange resin beads.

Firstly the gas holdup in the gas-liquid two-phase system was measured for use in the calculation of mass transfer coefficient for the three-phase system. The observed values of gas holdup agreed with those estimated by Akagawa's equation, being about $30 \%$ larger than those estimated by Hughmark's equation. Secondly the mass transfer coefficient was precisely obtained in the three-phase tube flow by measuring ion-exchange rate under the conditions of temperatures of 20 to $30^{\circ} \mathrm{C}$, slurry velocities of 0.07 to $3.0 \mathrm{~m} / \mathrm{s}$, and gas velocities of 0 to $2.0 \mathrm{~m} / \mathrm{s}$. The observed mass transfer coefficient increased with increases in temperatrue, slurry velocity, and gas velocity. The effect of gas velocity is more remarkable at low slurry velocity while that of slurry velocity should be marked at low gas velocity. In the correlation of mass tranfer coefficient, a parameter of energy dissipation rate was defined by Eq. (9), successfully expressing both effects of slurry velocity and gas velocity. The specific power group including the energy dissipation rate correlated all the data of mass transfer coefficient over a wide range of the conditions in the three-phase tube flow. The correlated experimental values almost coincided with the calculated ones by Eq. (8) previouly proposed for solid-liquid two-phase tube flow. The fact means that Eq.(8) is also applicalbe to the gas-liquid-solid three-phase tube flow with the energy dissipation rate defined by Eq. (9). 


\section{ACKNOWLEDGMENT}

The authors would like to thank the Asahi Glass Foundation for the Contribution to Industrial Technology for support of this work through a grant, and Mitsubishi Chemical Industries Ltd. for the supply of various kinds of ion exchange resin beads. The assistance of student collegues (Messrs. M. Oizumi, K. Sasaki, S. Miyata, K. Ishida and K. Endo) is also appreciated.

\section{NOMENCLATURE}

a interfacial area per unit volume of reactor, $6 e_{S} / D_{P}, \mathrm{~m}^{-1}$

c concentration of potassium ion, $\mathrm{kmol} / \mathrm{m}^{3}$

$c_{e}$ concentration of potassium ion at outlet, $\mathrm{kmol} / \mathrm{m}^{3}$

$c_{i}$ concentration of potassium ion at liquid-solid interface, $\mathrm{kmol} / \mathrm{m}^{3}$

$c_{o}$ concentration of potassium ion at inlet, $\mathrm{kmol} / \mathrm{m}^{3}$

$D$ diffusivity, $\mathrm{m}^{2} / \mathrm{s}$

$D_{P} \quad$ particle diameter, $\mathrm{m}$

$D_{T}$ tube diameter, $\mathrm{m}$

$e$ fractional holdup, $\mathrm{m}^{3} / \mathrm{m}^{3}$

$f$ friction factor for smooth tube

$g$ acceleration of gravity, $\mathrm{m} / \mathrm{s}^{3}$

\section{Greek}

$\varepsilon \quad$ energy dissipation rate per unit mass of liquid, $\mathrm{m}^{2} / \mathrm{s}^{3}$

v kinematic viscosity, $\mathrm{m}^{2} / \mathrm{s}$
$k_{\mathrm{L}} \quad$ liquid-solid mass transfer coefficient, $\mathrm{m} / \mathrm{s}$

$L$ reactor length, $\mathrm{m}$

$m_{d}$ delivered concentration of particle, $\mathrm{m}^{3} / \mathrm{m}^{3}$

$s$ cross sectional area of tube, $\mathrm{m}^{3}$

$S c$ Schmidt number, $v / D$

$S h$ Sherwood number, $\overline{\mathrm{k}_{\mathrm{L}}} D_{P} / \mathscr{D}$

$u$ velocity, $\mathrm{m} / \mathrm{s}$

$u_{i 0} \quad$ superficial velocity, $\bar{e}_{i} \bar{u}_{i}(i=G$, $\mathrm{L}, \quad S, \quad S \mathrm{~L}), \mathrm{m} / \mathrm{s}$

$u_{T} \quad$ velocity of three-phase flow, $u_{G 0}+u_{\mathrm{L} 0}+u_{S 0}, \mathrm{~m} / \mathrm{s}$

$\overline{\mathrm{u}}_{s}^{*}$ particle velocity on the basis of slurry, defined by Eq. (6), m/s

$V \quad$ sampled volume, $\mathrm{m}^{3}$

$x \quad$ axial distance from reactor inlet, $\mathrm{m}$

$\rho$ density, $\mathrm{kg} / \mathrm{m}^{3}$

$\rho_{T}$ density of three-phase flow, $\rho_{G} \overline{e_{G}}+\rho_{\mathrm{L}} \overline{e_{\mathrm{L}}}+\rho_{S} \overline{e_{S}} \mathrm{~kg} / \mathrm{m}^{3}$

$S L \quad$ slurry

0 superficial

\section{Superscript}

\section{Subscripts \\ G gas \\ $L \quad$ liquid \\ $S \quad$ solid}

averaged across cross-section of tube 


\section{REFERENCES}

Akagawa, K., 1957 : The flow of the Mixture of Air and Water II. The Relative Velocity in Horizontal, Inclined and Vertical Tubes, Trans. J. S. M. E. , Vol.23, No.128, 285-2 91.

Hatate, Y., et al., 1986 a : Gas Holdup and Pressure Drop in Three-Phase Vertical Flows of Gas-Liquid-Fine Solid Particles System, J. Chem. Eng. Japan, Vol.19, No.1, 56-61.

Hatate, Y., et al., 1986 b : Gas Holdup and Pressure Drop in Three-Phase Horizontal Flows of Gas-Liquid-Fine Solid Particles System, J. Chem. Eng. Japan, Vol.19, No.4, 330-335.

Hatate, Y., et al., 1987 : Heat Transfer Coefficient in Three-Phase Vertical Upflows of Gas-Liquid Fine Solid Particles System, J. Chem. Eng. Japan, Vol.20, No. 6, 568-574

Hughmark, G. A., 1962 : Holdup in Gas-Liquid Flow, Chem. Eng. Progr., Vol.58, No.4, 62-65.

Kataoka, T., Sato, N. and Ueyama, K., 1968 : Effective Liquid Phase Diffusivity in Ion Exchange, J. Chem. Eng. Japan, Vol.1, No.1, 38-42.

Kikuchi, K., 1984 : Correlation of Mass Transfer Coefficients from the Particle under Various Conditions. Dr. Eng. Thesis, Tohoku University.

Kikuchi, K., et al., 1987 : Effect of Inert Particle Concentration on Mass Transfer between Particles and Liquid in Solid-Liquid Two-Phase Upflow through Vertical Tubes and in Stirred Tanks, J. Chem. Eng. Japan, Vol.20, No.2, 134-140.

Levins, D. M. and Glastonbury, J. R., 1972 : Particle-Liquid Hydrodynamics and Mass Transfer in a stirred Vessel. Part-II. Mass Transfer, Trans. Instn. Chem. Engrs., Vol.50, 132-146.

Ohashi, H., et al., 1979 : Mass Transfer between Particles and Liquid in Solid-Liquid Two-Phase Upflow in Vertical Tubes, J. Chem. Eng. Japan, Vol.12, No.3, 190-195.

Ohashi, H. et al., 1980: Average Particle Velocity in Solid-Liquid Two-Phase Flow through Vertical and Horizontal Tubes, J. Chem. Eng. Japan, Vol.13, No.5, 343-349.

Ohashi, H., Sugawara, T. and Kikuchi, K., 1981: Mass Transfer between Particles and Liquid in Solid-Liquid Two-Phase Upflow in the Low-Velocity Region through Vertical Tubes, J. Chem. Eng. Japan, Vol.14, No.6, 489-491.

Ohashi, H. et al., 1982 : Mass Transfer between particles and Liquid in Solid-Liquid Two-Phase Flow through Horizontal Tubes, J. Chem. Eng. Japan, Vol.15, No.4, 311-31 3.

Sano, Y., Yamaguchi, N. and Adachi, T., 1974: Mass Transfer Coefficients for Suspended Particles in Agitated Vessels and Bubble Columns, J. Chem. Eng. Japan, Vol.7, No.4, 255-261.

Taitel, Y., Bornea, D. and Dukler, A. E., 1980 : Modelling Flow Pattern Transitions for Steady Upward Gas-Liquid Flow in Vertical Tubes, AIChE J. , Vol.26, No.3, 345-3 54

Toda, M., et al., 1982 : Transport of Solids by Gas-Liquid Upward Flow in Vertical Pipes, Kagaku Kogaku Ronbunshu, Vol.8, No.4, 380-386. 